\title{
THE ENERGETICS OF PASSIVE SUSPENSION FEEDING: ECOLOGICAL AND EVOLUTIONARY CONSEQUENCES FOR CRINOIDS.
}

\author{
BAUMILLER, Tomasz, K., Department of Earth and Planetary Sciences, Harvard \\ University, 20 Oxford Street, Cambridge, MA 02138, U.S.A.
}

Do organismal characteristics influence evolutionary histories of taxa? This important question has been answered in the affirmative for a variety of organisms, and here it is applied to the echinoderm class Crinoidea. The approach used in answering this question involves (1) identifying a relevant trait through functional analysis, (2) demonstrating its ecological significance, and (3) testing the hypothesis that the ecological characteristics affect evolutionary rates.

Crinoids, like all passive suspension feeders, depend on externally driven flows to supply them with necessary particulate nutrients. Particles are captured with feeding appendages which function as filters. Filters act as obstacles to the flow and their morphology influences how much fluid can be filtered at a given current velocity: fine filters, because of their higher resistance to flow, sample less fluid and fewer potential food items than coarse filters. This suggests that filter morphology may be important in controlling the distributions of crinoids among different environments: at low current velocities fine-filtered crinoids may not capture sufficient particulate nutrients to satisfy their energy needs.

To quantify the effect of filter morphology on particulate nutrient capture, an energy budget equation was solved for two crinoid morphologies representing the fine (pinnulate) and coarse (non-pinnulate) filters. In this equation, energy inputs in the form of captured and metabolized nutrients had to exceed energy expenditures, expressed as the standard metabolic rate. The solution of the equation showed that the current velocity below which crinoids are at an energy deficit is higher for the finefiltered (pinnulate) than the coarse-filtered (non-pinnulate) taxa.

The higher minimum velocity of fine-filtered crinoids restricts them to environments with higher current velocities; coarse-filtered taxa are less constrained and may occupy a broader range of environments. This pattern is borne out by the distribution of Mississippian crinoids studied by Kammer and Ausich (1987). With regard to current velocities, the fine-filtered crinoids may be described as "specialists" and the coarse-filtered crinoids as "generalists". The specialist/generalist strategies of the two groups suggest an evolutionary scenario in which the fine-filtered crinoids are more prone to speciation and extinction.

To test the above scenario the evolutionary rates of two morphological groups, fine-filtered crinoids (camerates) and coarse-filtered crinoids (non-pinnulate Paleozoic crinoids), were compared. As predicted, the former group had higher extinction and origination rates. A "bootstrapping" technique revealed that the differences in extinction rates were statistically significant $(\mathrm{P}<0.05)$.

The filter morphology-evolutionary rate scenario, however, fails to predict the durations of two other fine-filtered (pinnulate) crinoid groups: the Paleozoic cladids and their descendants, the post-Paleozoic articulates. Though fine-filtered, these taxa had broad environmental distributions and the lowest extinction rates among the Crinoidea. They are also the only crinoids with muscular arm articulations. This "evolutionary innovation", by allowing a greater degree of morphological and behavioral flexibility, allowed these crinoids to occupy a broader range of environments and may in part explain their "anomalous" evolutionary rates. 